\title{
An investigation of the emotions elicited by hospital clowns in comparison to circus clowns and nursing staff
}

\author{
Sarah Auerbach \\ Jennifer Hofmann \\ Tracey Platt \\ Willibald Ruch \\ Department of Psychology, University of Zurich, Switzerland
}

\begin{abstract}
The present research aims at identifying emotional states induced in observers of hospital clown interventions utilizing a list of clown-specific ratings, the 29 Clown Emotion List (CLEM-29, Auerbach et al. 2012a). Study 1 investigated whether hospital clowns elicit emotional states other than those already covered by scales representing existing models of emotional states. One hundred and nineteen adults watched videos of hospital clowns and circus clowns. After each video, they completed a general mood scale, a humour-related mood scale, the CLEM-29, and indicated the global intensity of positive and negative feelings towards each video. Results showed that emotional states elicited by hospital clowns go beyond states represented in general mood scales. Some elements of the CLEM-29 relating to humour and amusement overlapped with existing models of mood, but many other emotional qualities like "feeling connected to the clown" or feeling "appreciated" were not well represented. Some of the clown-specific ratings best predicted the positive experiences towards the videos. In Study 2, 183 adults watched 15 videos of hospital clown interventions, circus clown performances and nurse-patient interactions, and filled in the CLEM-29. Four factors emerged from a factor analysis of the ratings: amusement, transcendence, arousal, and uneasiness. Both circus and hospital clowns elicited amusement, but only the hospital clowns additionally elicited feelings of transcendence (i.e., feeling privileged and appreciated). Nurses also elicited transcendent experiences without being amusing. This research shows that prior studies underestimated emotional states elicited by hospital clowns, which go beyond a typical humour response.
\end{abstract}

Keywords: clowns, emotions, humour, nurses, positive psychology. 


\section{Introduction: Clowning - from the circus to hospital}

Over the last two decades, clowns have found their way into hospitals, nursing homes and psychiatric institutions. Ruch et al. (2013) argued that these humorous interactions between clowns and patients in health care settings could be seen as positive interventions within the broader framework of positive psychology. The latter is aimed at studying what is best in people and what facilitates people to flourish. Ruch et al. suggest that many institutions (e.g., the Red Noses, Le Rire Medecin, Theodora Foundation, or Soccorso Clown) are interested in strengthening the positive role hospital clowns can play in health care settings. They also identify differences between these specific clowns and others; "hospital clowns must have a comprehensive understanding of the care setting, establish a personal relationship to the patient, distract patients from their daily routines, pain and negative affect, and contribute to well-being and good atmosphere in care settings."

Although there seems to be a widely accepted understanding of the positive impact clowns can have in these types of settings, it is still an understudied topic and empirical studies are rare. Ruch et al. (2013) point out that earlier research has focused on increases in positive experiences or decreases in negative experiences in clown interactions, while other, more fine-grained processes and alterations of emotional states of patients and observers are omitted. A brief (and incomplete) review of the literature summarizes the findings: Looking at positive outcome variables, studies found positive attitudes towards and acceptance of the clowns on the part of patients and staff (e.g., Linge 2008, 2011, 2012; Wild et al. 2007), short-term increases in self- and parent-reported psychological well-being (Pinquart et al. 2011), enhanced trait and state ratings of cheerfulness (Hirsch et al. 2010), and enhanced unspecific positive affect (as measured by a bipolar "happy vs. sad" scale; Costa Fernandes and Arriaga 2010). Looking at the reduction of negative outcome variables in clown groups compared to control groups, studies found less self-reported worries, self-reported anxiety and observed anxiety in children undergoing surgery (e.g., Costa Fernandes and Arriaga 2010; Golan et al. 2009; Vagnoli et al. 2005; Vagnoli et al. 2010), reduced symptoms of depression after humour intervention in psychogeriatric patients (Hirsch et al. 2010), less self reported pain (e.g., Bertini et al. 2011), and reduced disruptive behaviour (Higueras et al. 2006). Looking at medical and physical changes, studies reported a reduction of hyperinflation in severe obstructive lung disease patients (Brutsche et al. 2008), an increased pregnancy rate in women entertained by a clown after in vitro fertilization (Friedler et al. 2011), an earlier disappearance of pathological symptoms, a higher state of relaxation, and less pain (Bertini et al. 2011), and increased pain tolerance while watching a humorous film (e.g., Stuber et al. 2009; Zweyer et al. 2004). Hence, these studies describe psychological or physical effects in patients involved in or observing clown interactions or humorous films. It is argued that clowns can elicit positive emotional states in their interaction partners, yet a detailed investigation of these states (especially at the level of single facets of affectivity) is missing.

\subsection{The role of emotional states}

A full theoretical account on the approaches to investigate emotional states has been given by Ruch et al. (2013). Hence, this will only be briefly described here and the reader will find a full overview in the Ruch et al. paper. General models, which differentiate between positive and negative affectivity, such as Watson and Tellegen's (1985), play a dominant role in this area. Those two dimensions are considered to exist independent from each other. Watson and Tellegen differentiate between affective states within their two broad dimensions. However, other researchers have proposed other theoretical frameworks for the assessment of such states. One of these is Janke et al.'s (2003) Mood Rating Inventory (BSKE [EWL]; the short version of the German Adjective Check List, EWL), which is sensitive to changes in 
momentary affective states. The usage of a broad instrument such as the BSKE (EWL) allows testing the role of single states (24 in total) besides the two broader dimensions of positive (PA) and negative affectivity (NA). Ruch et al. (2013) also suggested accounting for individual differences in a person's propensity to experience the emotion of exhilaration (i.e., the process of making cheerful or the temporary rise and fall of a cheerful state; Ruch 1993), which has been identified as the emotional response to humour. The interplay of humour as an elicitor, humour-related states and traits and the behavioural, physiological and experiential components of exhilaration have been studied extensively; for an overview see Ruch and Hofmann (2012).

Based on the description given by Ruch et al. (2013) we expect that hospital clowns induce a state of high PA (and possibly low NA) in the observers, and, when testing subsets of PA more closely, a state of high exhilaration/amusement. However, studies in the area of clown research and adjacent areas propose that hospital clowns might additionally elicit emotional states in patients that go beyond global positive affect and exhilaration.

\subsection{Hospital clowns: Positive affectivity, exhilaration and beyond?}

One of the main aims of this study is to find similarities and differences between hospital clowns and other professionals in their effect on individuals when observing their interaction with patients. Adams (2002) speaks of a revolution of care and states that the hospital clowns' work is a combination of humour and love. Hospital clowns, like other humour professionals (e.g., circus clowns), are expected to be perceived as funny, and to elicit a rise in exhilaration accompanied by smiling and laughter. This distinguishes them from health professionals, whose primary task is to care for people (which might or might not be accompanied by humour). But there might be other emotional reactions triggered by a hospital clown that exceed exhilaration. The love strategy (Adams 2002) might be the overlap between a hospital clown and health professionals (e.g., nurses), as both require high levels of empathy and intuition (love) when dealing with patients. Hence, hospital clowns seem to integrate approaches from both nurses and circus clowns: Being empathic like a caring nurse, but also eliciting humour and joy, like an entertaining circus clown. Ruch et al. (2013) review literature on studies that have dealt with the role of clown interventions perceived by health care professionals and patients (e.g., Kingsnorth et al. 2010; Linge 2011). Thus far, there is no comprehensive study on the emotional states experienced by observers of such interactions. One of the obstacles in this line of research is that there is no research instrument covering a broad range of emotional states elicited by clowns working in hospitals. Ideally, such a list is compiled in close collaboration with clowns themselves for accounting for their viewpoint and practical experiences. It is argued that a better understanding of the emotional reactions elicited by clowns can help advancing the field on a theoretical level, but can also enrich the practical work of hospital clowns.

\section{Aim of the present research}

In a first attempt to understand the emotional reactions of individuals to hospital clowns, this research only concerns observers of the situation. The aim is to identify the emotional experiences induced in observers watching videos of hospital clown interventions, and to compare them to emotional experiences induced in observers while watching videos of circus clowns and nurses. These groups were selected because they overlap with the work of a hospital clown; circus clowns share some skills and the capacity to entertain and nurses share, among others, the caring elements. As no comprehensive research instrument for the assessment of clown-specific states is available, a list of emotional states is obtained with the 
help of interviewing expert clowns on their perception of emotions elicited during the intervention and laypersons by free associations in response to clown interventions that they see. In two studies, this list of emotional states is examined for its usefulness in the evaluation of hospital clown interventions, which will be tested according to the following three criteria.

The first criterion is that the clown-specific list represents state ratings sufficiently different from existing scales of emotional states. The second criterion is that the clownspecific list should show incremental validity when predicting the total amount of positive and negative affect in response to the films; i.e., their prediction should exceed the ones by existing mood scales. Study 1 applies the two criteria and investigates the empirical overlap between the clown-specific state ratings and those already covered by scales of a general model of PA and NA, as well as a humour-related model of emotional states. Furthermore, it is investigated whether the clown-specific state ratings perform better in the prediction of positive and negative experiences while watching a clown scene than scales of existing mood models, and thus add incremental validity to the prediction. The third criterion is that the clown-specific ratings can show the unique effect of hospital clowns on the emotional responses of observers in comparison to other groups: nurses and circus clowns, which will be investigated in Study 2.

\section{Material Generation}

In both studies, video clips of clowns and nurses are presented to participants who are asked to indicate their emotional reactions to observing the clips. For this purpose, a collection of video clips is needed which contains circus clown performances, hospital clown interactions and nursing interactions. Moreover, it is necessary to compile a list of emotional states relevant in the context of a clown performance, on which the participants rate their felt emotional states.

\subsection{Cheerfulness-Empathy Video Collection (CEVC)}

The Cheerfulness-Empathy Video Collection (CEVC; Auerbach et al. 2012b) is a collection of 15 video clips, five each preselected by the authors to be typical for the work of circus clowns, hospital clowns, and nurses in their respective settings. The clips of hospital clown interventions were filmed in hospital and nursing home settings involving children and adults (e.g., male hospital clown playing waiter while helping at the lunch table). The five circus clowns clips show performances to audiences on stage (e.g., male clown putting table tennis balls in his mouth and making funny grimaces). The nurse clips show interactions between a nurse and one or more persons in medical situations (e.g., female nurse interacting with a child with cancer). The video clips for the two studies were generated in two stages. The first stage required three trained observers to watch several hours of archived materials and live performances of different hospital and circus clowns, as well as clips involving nurses, stemming from a variety of sources (e.g., documentary on hospital clowns in nursing homes, a video by the Austrian Red Noses Association, from the platform www.youtube.com). A pool of 90 interactions (roughly 30 of each category) was scrutinized and finally 30 clips (varying between 1:01 and 2:30 minutes in lengths) were chosen for stage two. These clips were rated on a 7-point scale ("How strong did the video clip elicit the following reactions?") on dimensions relevant for helping distinguish the types of clips (funniness, empathy, silliness, cheerfulness, joy, affection, laughter, exhilaration). In brief, the results showed that both hospital and circus clown clips elicited amusement, the hospital clown also elicited empathy, and the circus clown also elicited silliness. The nurse clips did elicit affection and empathy, but not amusement. A final selection of 15 videos consisting of five hospital 
clowns, five circus clowns and five nurses was chosen based on several criteria (e.g., comparability in terms of lengths, no offensive material, no disturbing or non-relevant information, etc.).

\subsection{The 29 Clown Emotion List (CLEM-29)}

The 29 Clown Emotion List (CLEM-29; Auerbach et al. 2012a) consists of 29 single ratings some of which are presented as single adjectives (e.g., touched) and others as short phrases (e.g., associated with the clown). Individuals rate their current experience on 7-point Likert scale ranging from 1 (= not at all) to 7 (= very strongly). The 29 ratings were drawn from two sources. First, three professional hospital clowns were asked to generate terms that best described their perception of the clown-audience interaction. They were instructed to draw on their experience and describe all thoughts and feelings they were told by the audience that they encountered during the clown interaction. They gave a list of 42 positive and five negative experiences. Second, a sample of 19 German-speaking adults $(26.3 \%$ male, ages 24 to 66 years; $M=39.89, S D=16.57$ ) freely associated their thoughts and feelings to ten randomly presented videos of circus clowns and hospital clowns from the CEVC. A total of 23 positive and 28 negative responses relating to circus clowns, and a list of 34 positive and six negative responses relating to hospital clown interactions were initially compiled by these laypersons. By eliminating redundant words (synonyms), words not relating to emotional states (e.g., word describing cognitive states) and words depicting broader emotion categories (that would be covered by more unspecific mood scales) in all lists, a final set of 29 adjectives and short phrases (CLEM-29) was derived. Some of the experiences cover core elements of affective states induced by clowns (e.g., exhilarated, playful), while others refer to states that do not apply to every clown, and not in every situation (e.g., flirty, overexcited, seduced, touched). It is noteworthy that the expert clowns already mentioned all adjectives and short phrases that were finally chosen. Of those, the expert clowns stated that all but four experiences were positively connoted. It is noteworthy that they also understood the term schadenfreude in a positive way, meaning that the patient is able to laugh about the clumsiness of the clown. The negative ones are: fearful, threatened, creepy, and overexcited [1].

\section{Study 1}

The purpose of Study 1 is twofold. First, the relationships between the empirically derived clown-specific emotional experiences and existing models of emotional states will be examined. It is hypothesized that some of the emotional states elicited by clowns can be located in a general model of mood within global PA, and more precisely within feelings related to humour and laughter (e.g., cheerfulness). In contrast, we expect that clowns elicit a variety of feelings unique to clowning, which are not strongly related to existing models of mood. Second, it will be examined whether the clown specific ratings contribute to the prediction of global positive and negative feelings while watching video clips showing clown interactions. It is hypothesized that the clown-specific ratings outperform general scales of emotional states in the prediction of the evaluation of the feelings towards the videos, and thus add incremental validity to the prediction.

\subsection{Method}

\subsubsection{Participants}


The sample consisted of 119 German-speaking adults (48.7\% female) aged between 18 and 73 years $(M=30.66, S D=13.53)$, and was a mixed sample of students and well-educated adults. Participants were recruited via personal contacts and at the university.

\subsubsection{Instruments}

The state form of the State-Trait-Cheerfulness Inventory (STCI-S<30>; Ruch et al. 1997) assesses humour-related states, and can be subsumed into three scales: state cheerfulness, state seriousness, and state bad mood. In the present study, a short version consisting of 18 items (STCI-S $<18>$ ) was used. People rate their current mood state on a four-point answer format from 1 (= strongly disagree) to 4 (= strongly agree). Item samples are "I feel merry" (state cheerfulness), "I am in a serious frame of mind" (state seriousness), and "I feel grouchy" (state bad mood). In the present study the scales yielded Cronbach's alpha coefficients between .76 and .90 .

The Mood Rating Inventory (BSKE [EWL]; Janke et al. 2003) is a multidimensional mood checklist consisting of 24 items, which can be subsumed into subscales, which then can be subsumed into the two broad domains of PA and NA. Each item consists of a noun and two adjectives describing the mood, and participants indicate on a Likert scale ranging from 1 (= not at all) to 7 (= very strongly) to what degree the scale applies to their present state. The higher order domain of PA consists of the subscales inner relaxation, cheerfulness [2], and vigour. The higher order scale NA consists of the subscales agitation, irritation, anxiety/ sadness, and deactivation.

The 29 Clown Emotion List (CLEM-29; Auerbach et al. 2012a) as described in section 3.2 was used to assess clown-specific emotional states.

\subsubsection{Procedure}

Participants were presented two short video clips from the CEVC in random order, one circus clown (male clown putting table tennis balls in his mouth and making funny grimaces) and one hospital clown (male hospital clown gives a little miracle to an old man: He puts a flying bird on his finger) video. The two videos were chosen to represent a prototypical circus or hospital clown scene. After watching each video, participants completed the STCI-S $\langle 18\rangle$, followed by the BSKE (EWL), and then the CLEM-29. Finally, they were asked to indicate the intensity of their global positive and negative feelings while watching the clown videos on two 7-point Likert-Scales ranging from 1 (= not at all) to 7 (= very strongly). The study was conducted via an online data collection program.

\subsection{Results}

\subsubsection{CLEM-29 within existing models of emotional states}

Each CLEM-29 rating was correlated (Pearson's correlations) with, and predicted (multiple regression, method: stepwise) by a) the BSKE (EWL) subscales of PA (inner relaxation, cheerfulness, vigour; Table 1), the BSKE (EWL) subscales of NA (agitation, irritation, anxiety/sadness, deactivation; Table 2), and c) the STCI-S $\langle 18\rangle$ scales (cheerfulness, seriousness, and bad mood; Table 3). This was done separately for both clown videos. To avoid inflation of Type I error due to multiple testing, the alpha was adjusted in all analyses according to the Bonferroni-correction, that is, for each criterion, the alpha (.05) was divided by the number of predictors. When interpreting the correlations in Tables 1 and 2, only coefficients $r \geq .23$ should be considered, as they were significant $(p<.05)$ after the alphaadjustment. In Table 3, only coefficients $r \geq .24$ should be interpreted. First, relations between the clown-specific ratings (CLEM-29) and the general model of mood (BSKE [EWL]) are presented (see Tables 1 and 2). 
Table 1. Correlations between the CLEM-29 Ratings and the Scales of Positive Affectivity of the BSKE (EWL), and Results of Regression Analyses

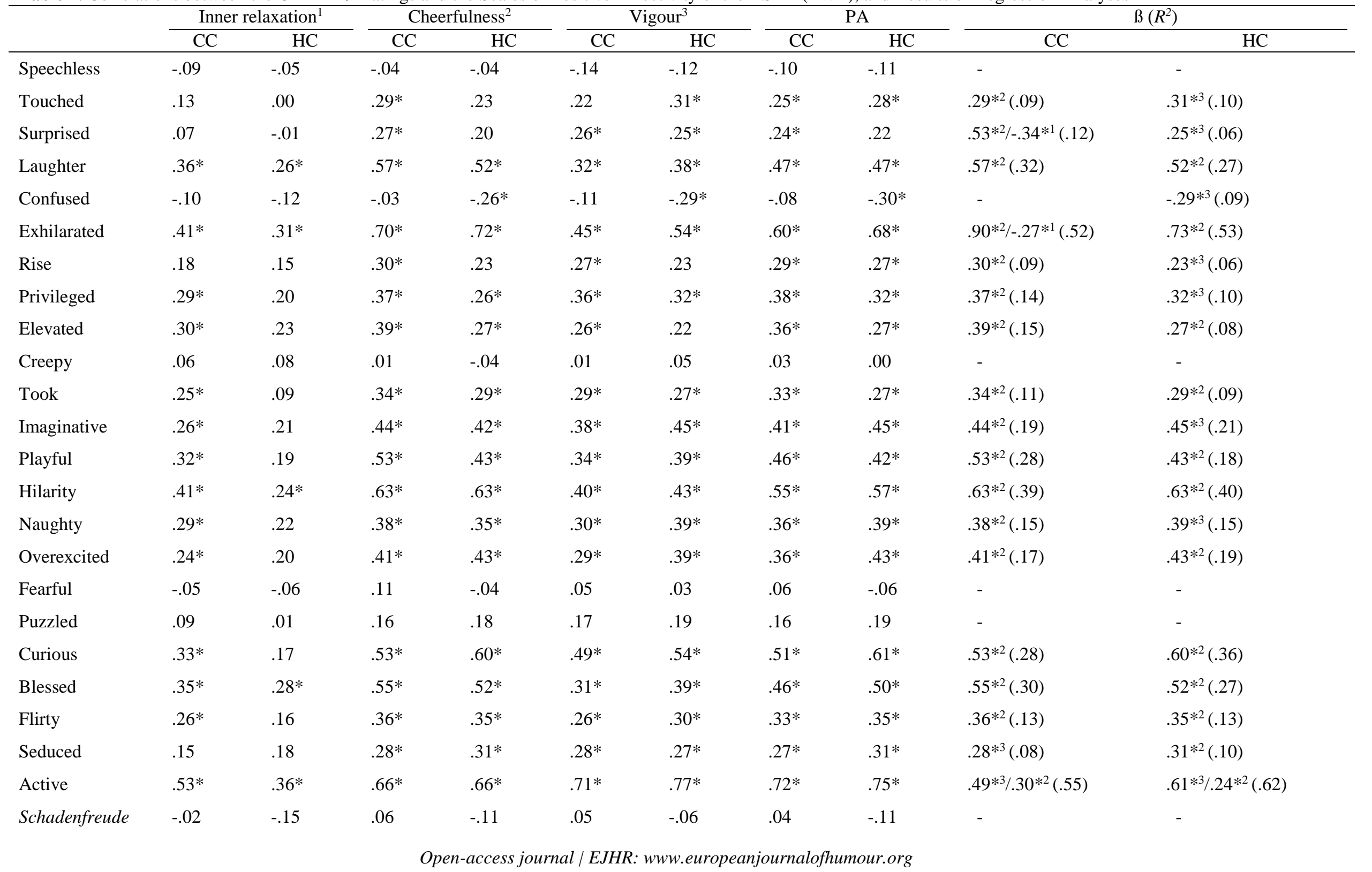


European Journal of Humour Researchl(3\&4)

\begin{tabular}{|c|c|c|c|c|c|c|c|c|c|c|}
\hline Impressed & .20 & .09 & $.36^{*}$ & $.35^{*}$ & $.42 *$ & $.44 *$ & $.38^{*}$ & $.40 *$ & $.42 * 3(.18)$ & $.44 *^{3}(.19)$ \\
\hline Associated & $.29 *$ & .07 & $.41 *$ & $.28 *$ & $.41 *$ & $.38 *$ & $.42 *$ & $.33 *$ & $.41 *^{3}(.17)$ & $.38^{* 3}(.14)$ \\
\hline Threatened & .13 & -.14 & .16 & .02 & .11 & -.09 & .15 & -.04 & - & - \\
\hline Freed & $.33^{*}$ & .20 & $.44^{*}$ & $.47 *$ & $.39 *$ & $.44 *$ & $.44^{*}$ & $.50 *$ & $.44 * 2(.19)$ & $.47 * 2(.22)$ \\
\hline Appreciated & $.37 *$ & .19 & $.43^{*}$ & $.38^{*}$ & $.38 *$ & $.30 *$ & $.44^{*}$ & $.38 *$ & $.43 * 2(.18)$ & $.38 * 2(.15)$ \\
\hline
\end{tabular}

Note. $N=113$. Coefficients of regression analysis are beta-coefficients ( $R^{2}$ in parentheses). Method of regression $=$ Stepwise. In case no variable entered the regression, no

coefficients are presented $(-)$. Indices $\left({ }^{1}\right.$ to $\left.{ }^{3}\right)$ indicate significant predictors in the regression analysis. Rise = Rise above yourself; Took $=$ Took something away from it; Laughter $=$ Burst into laughter; Associated $=$ Associated with the clown; $\mathrm{CC}=$ Circus clown; $\mathrm{HC}=$ Hospital clown; PA = Positive affectivity.

$* p<.05$ (Bonferroni-corrected). 
European Journal of Humour Research1(3\&4)

Table 2. Correlations between the CLEM-29 Ratings and the Scales of Negative Affectivity of the BSKE (EWL), and Results of Regression Analyses

\begin{tabular}{|c|c|c|c|c|c|c|c|c|c|c|c|c|}
\hline & \multicolumn{2}{|c|}{ Agitation $^{1}$} & \multicolumn{2}{|c|}{ Irritation $^{2}$} & \multicolumn{2}{|c|}{ Anxiety/sadness } & \multicolumn{2}{|c|}{ Deactivation $^{4}$} & \multicolumn{2}{|c|}{ NA } & \multicolumn{2}{|c|}{$\beta\left(R^{2}\right)$} \\
\hline & $\mathrm{CC}$ & $\mathrm{HC}$ & $\mathrm{CC}$ & $\mathrm{HC}$ & $\mathrm{CC}$ & $\mathrm{HC}$ & $\mathrm{CC}$ & $\mathrm{HC}$ & $\mathrm{CC}$ & $\mathrm{HC}$ & $\mathrm{CC}$ & $\mathrm{HC}$ \\
\hline Speechless & $.24 *$ & .23 & .11 & .05 & .21 & .07 & .13 & .09 & .22 & .14 & $.24 * 1(.06)$ & - \\
\hline Touched & $.30 *$ & .22 & -.13 & -.15 & -.04 & -.07 & -.15 & $-.25 *$ & -.05 & -.13 & $.35^{* 1} /-.23 *^{* 4}(.14)$ & $-.30 * 4 / .27 * 1(.13)$ \\
\hline Surprised & $.27 *$ & $.28 *$ & -.10 & -.04 & -.06 & -.08 & -.16 & -.23 & -.05 & -.06 & $.32 * 1 /-.23 * 4(.13)$ & $.33 * 1 /-.28 * 4(.15)$ \\
\hline Laughter & .19 & .17 & $-.31 *$ & $-.31 *$ & $-.26 *$ & $-.25 *$ & $-.27 *$ & $-.26 *$ & $-.25 *$ & $-.25 *$ & $-.31 * 2 / .32 * 1 /-.23 * 4(.22)$ & $-.45 * 2 / .35 * 1(.20)$ \\
\hline Confused & $.38^{*}$ & $.34^{*}$ & $.27 *$ & $.47 *$ & $.31 *$ & $.37 *$ & $.25^{*}$ & $.32 *$ & $.40^{*}$ & $.50 *$ & $.38^{* 1}(.14)$ & $.47 * 2(.22)$ \\
\hline Exhilarated & .10 & .14 & $-.40 *$ & $-.44 *$ & $-.29 *$ & $-.30 *$ & $-.36 *$ & $-.42 *$ & $-.36 *$ & $-.40 *$ & $-.36 * 2 /-.29 * 4 / .26 * 1(.27)$ & $-.47 * 2 / .37 * 1 /-.29 * 4(.38)$ \\
\hline Rise & .16 & .23 & -.08 & .01 & -.02 & .09 & -.13 & -.02 & -.06 & .07 & - & - \\
\hline Privileged & .18 & $.38^{*}$ & -.09 & -.03 & -.03 & .06 & -.21 & -.15 & -.09 & .03 & - & $.38^{* 1}(.19)$ \\
\hline Elevated & .23 & $.34^{*}$ & -.16 & -.11 & -.09 & .00 & -.12 & -.10 & -.08 & .00 & - & $.45 * 1 /-.29 * 2(.19)$ \\
\hline Creepy & .23 & $.35^{*}$ & .14 & $.34 *$ & .18 & $.32 *$ & .05 & .08 & .18 & $.34 *$ & - & $.26^{* 1} . / 24 * 2(.17)$ \\
\hline Took & .16 & .16 & -.17 & -.13 & -.04 & .02 & -.17 & -.16 & -.11 & -.08 & - & - \\
\hline Imaginative & .20 & $.28^{*}$ & -.06 & $-.26 *$ & -.02 & -.04 & $-.30 *$ & $-.26 *$ & -.11 & -.16 & $-.36 * 4 / .28 * 1(.16)$ & $.46^{* 1 /-.44 * 2}(.24)$ \\
\hline Playful & $.32 *$ & $.32 *$ & -.22 & $-.26 *$ & -.14 & -.12 & $-.24 *$ & -.21 & -.14 & -.14 & $.44 * 1 /-.25 * 4 /-.24 * 2(.25)$ & $.50 * 1 /-.45 * 2(.28)$ \\
\hline Hilarity & .06 & .11 & $-.33 *$ & $-.42 *$ & $-.31 *$ & $-.24 *$ & $-.30 *$ & $-.33 *$ & $-.32 *$ & $-.34 *$ & $-.33 * 2(.11)$ & $-.54 * 2 / .32 * 1(.26)$ \\
\hline Naughty & .21 & $.35^{*}$ & -.17 & -.13 & -.15 & -.04 & -.20 & -.22 & -.13 & -.07 & - & $.47 * 1 /-.32 * 2(.21)$ \\
\hline Overexcited & $.36^{*}$ & $.48^{*}$ & -.08 & -.06 & .03 & .00 & -.17 & -.17 & -.01 & .03 & $.42 * 1 /-.27 * 4(.20)$ & $.59 * 1 /-.30 * 2(.30)$ \\
\hline Fearful & $.29 *$ & $.47 *$ & .06 & $.30 *$ & .21 & $.42 *$ & .01 & .05 & .16 & $.36^{*}$ & $.29 * 1(.09)$ & $.36 * 1 / .28 * 3(.29)$ \\
\hline Puzzled & .14 & .18 & -.06 & -.14 & -.06 & -.16 & -.10 & -.16 & -.05 & -.11 & - & - \\
\hline Curious & .19 & .13 & $-.26 *$ & $-.31 *$ & -.22 & $-.25 *$ & $-.28 *$ & $-.31 *$ & -.23 & $-.28 *$ & $-.26 * 4 / .31 * 1 /-.24 * 2(.20)$ & $-.32 * 4(.10)$ \\
\hline Blessed & .14 & .23 & $-.29 *$ & $-.31 *$ & -.17 & -.15 & -.14 & -.17 & -.18 & -.17 & $-.29 * 2(.08)$ & $-.47 * 2 / .42 * 1(.24)$ \\
\hline Flirty & $.25^{*}$ & $.29 *$ & -.12 & -.15 & -.06 & -.03 & -.04 & -.01 & -.01 & .01 & $.25^{* 1}(.06)$ & $.42 * 1 /-.31 * 2(.17)$ \\
\hline Seduced & .15 & $.36^{*}$ & -.08 & -.05 & -.04 & -.08 & -.13 & -.01 & -.06 & .06 & - & $.46 * 1 /-.26 * 3(.18)$ \\
\hline Active & -.04 & .17 & $-.36^{*}$ & $-.34 *$ & $-.37 *$ & $-.31 *$ & $-.59 *$ & $-.59 *$ & $-.51 *$ & $-.42 *$ & $-.59 * 4(.35)$ & $-.54 * 4 / .35 * 1 /-.25 * 2(.46)$ \\
\hline Schadenfreude & .18 & $.24 *$ & .17 & .22 & .13 & .11 & -.03 & .08 & .13 & .21 & - & $.24 * 1(.06)$ \\
\hline Impressed & .13 & .19 & -.15 & -.13 & -.04 & -.08 & $-.27 *$ & $-.24 *$ & -.16 & -.13 & $-.27 * 4(.07)$ & $-.28 * 4 / .23 * 1(.11)$ \\
\hline Associated & .09 & $.31 *$ & $-.24 *$ & -.17 & -.17 & .05 & $-.35 *$ & -.19 & $-.27 *$ & -.06 & $-.35^{* 4}(.12)$ & $.44 * 1 /-.34 * 2(.19)$ \\
\hline Threatened & .02 & .08 & .02 & .03 & .00 & .22 & -.01 & .02 & .01 & .09 & - & - \\
\hline Freed & .09 & $.24^{*}$ & $-.26^{*}$ & -.17 & -.17 & -.10 & -.20 & -.18 & -.21 & -.11 & $-.26 * 2(.07)$ & $.37 * 1 /-.31 * 2(.14)$ \\
\hline Appreciated & .12 & $.27 *$ & -.13 & -.20 & -.07 & -.09 & -.15 & -.14 & -.10 & -.09 & - & $.41 * 1 /-.36 * 2(.18)$ \\
\hline
\end{tabular}

Note. $N=113$. Coefficients of regression analysis are beta-coefficients ( $R^{2}$ in parentheses). Method of regression $=$ Stepwise. In case no variable entered the regression, no coefficients are presented (-). Indices $\left({ }^{1}\right.$ to $\left.{ }^{4}\right)$ indicate significant predictors in the regression analysis. Rise $=$ Rise above yourself; Took $=$ Took something away from it; Laughter $=$ Burst into laughter; Associated $=$ Associated with the clown; $\mathrm{CC}=$ Circus clown; $\mathrm{HC}=$ Hospital clown; NA $=$ Negative affectivity .

$* p<.05$ (Bonferroni-corrected). 
Table 1 shows that, in line with the hypothesis, PA correlated with several CLEM-29 ratings, with the highest correlations $(r>.50)$ occurring between the PA-subscale cheerfulness and exhilarated, active, hilarity, burst into laughter, curious, and blessed. Numerically lower, but still significant correlations were obtained between PA and touched, surprised, rise above yourself (only circus clown), elevated, privileged, took something away from it, imaginative, naughty, overexcited, flirty, seduced, impressed, associated with the clown, freed, and appreciated (both clowns). Looking at the predictive validity of the subscales of PA for the CLEM-29 ratings, one can see that mostly the scale cheerfulness predicted ratings from the CLEM-29. This subscale explained a high percentage of variance in those CLEM-29 ratings relating to amusement (e.g., 53\% explained variance at the rating exhilarated and $40 \%$ explained variance at the rating hilarity for the hospital clown), suggesting that they conceptually overlapped. For most of the other ratings (especially the ones not referring to a cheerful state), the proportion of explained variance was rather low $(<20 \%)$. As expected, a great proportion of the variance of the CLEM-29 ratings was not explained by the scales of PA, and some of the CLEM-29 ratings (especially those related to NA) were not related to the model of PA at all; i.e., no predictor entered the regression analysis. These ratings were speechless, confused, creepy, fearful, puzzled, schadenfreude, and threatened.

As regards the domain of NA (Table 2), correlations were lower, but mostly in a plausible direction: negatively connoted ratings from the CLEM-29 (confused, creepy, fearful, schadenfreude) correlated positively with higher order NA, and positively connoted ratings from the CLEM-29 correlated negatively with NA. It was striking that for the subscales of NA for both types of clowns, many CLEM-29 ratings (e.g., surprised, overexcited, flirty, playful) were positively correlated with the subscale agitation, which subsumes a state of psychological and physiological arousal. Again, many CLEM-29 ratings were not represented in the general model of NA.

Next, the relations between the clown-specific ratings and the model of humour-related states were examined. Therefore, each CLEM-29 rating was correlated (Pearson's correlations) with, and predicted (multiple regression, method: stepwise) by the STCI-S $<18>$ scales cheerfulness, seriousness, and bad mood, separately for both clown videos. Results can be seen in Table 3. 
European Journal of Humour Researchl(3\&4)

Table 3. Correlations between the CLEM-29 Ratings and the STCI-S $<18>$ Scales, and Results of Multiple Regression Analyses

\begin{tabular}{|c|c|c|c|c|c|c|c|c|}
\hline & \multicolumn{2}{|c|}{ Cheerfulness $^{1}$} & \multicolumn{2}{|c|}{ Seriousness $^{2}$} & \multicolumn{2}{|c|}{ Bad mood ${ }^{3}$} & \multicolumn{2}{|c|}{$\beta\left(R^{2}\right)$} \\
\hline & $\mathrm{CC}$ & $\mathrm{HC}$ & $\mathrm{CC}$ & $\mathrm{HC}$ & $\mathrm{CC}$ & $\mathrm{HC}$ & $\mathrm{CC}$ & $\mathrm{HC}$ \\
\hline Speechless & .06 & .00 & .21 & .15 & .13 & .01 & - & - \\
\hline Touched & $.45^{*}$ & $.28 *$ & -.08 & .14 & -.18 & -.13 & $.45^{* 1}(.20)$ & $.35 * 1 / .24 * 2(.13)$ \\
\hline Surprised & $.34^{*}$ & .17 & .02 & .15 & -.13 & -.12 & $.34 * 1(.12)$ & - \\
\hline Laughter & $.68^{*}$ & $.58 *$ & -.22 & -.10 & $-.32 *$ & $-.36^{*}$ & $.68 * 1(.46)$ & $.58 * 1(.33)$ \\
\hline Confused & -.02 & $-.27 *$ & .21 & .20 & $.25^{*}$ & $.41^{*}$ & $.25 * 3(.06)$ & $.41 *^{3}(.17)$ \\
\hline Exhilarated & $.81 *$ & $.69 *$ & $-.36^{*}$ & -.20 & $-.48 *$ & $-.52 *$ & $.81^{* 1}(.66)$ & $.69 * 1(.48)$ \\
\hline Rise & $.36^{*}$ & .14 & -.05 & .09 & -.14 & -.05 & $.36 * 1(.13)$ & - \\
\hline Privileged & $.39 *$ & .22 & .05 & $.25^{*}$ & -.17 & -.02 & $.39 * 1(.15)$ & $.34 * 2 / .31 * 1(.15)$ \\
\hline Elevated & $.43^{*}$ & $.26^{*}$ & -.04 & .13 & -.22 & -.10 & $.43 * 1(.19)$ & $.26 * 1(.07)$ \\
\hline Creepy & .04 & -.07 & .13 & .09 & .14 & $.24^{*}$ & - & $.24 * 3(.06)$ \\
\hline Took & $.37 *$ & .20 & .07 & .04 & -.18 & -.13 & $.45 * 1 / .23 * 2(.18)$ & - \\
\hline Imaginative & $.41^{*}$ & $.44^{*}$ & -.05 & .11 & -.12 & $-.24 *$ & $.41 * 1(.17)$ & $.51 * 1 / .25 * 2(.25)$ \\
\hline Playful & $.57 *$ & $.48^{*}$ & -.05 & .08 & $-.27 *$ & $-.31 *$ & $.57 * 1(.32)$ & $.55^{* 1} / .24 * 2(.28)$ \\
\hline Hilarity & $.66^{*}$ & $.61 *$ & $-.25^{*}$ & -.06 & $-.38 *$ & $-.48 *$ & $.66 * 1(.44)$ & $.61 * 1(.37)$ \\
\hline Naughty & $.40^{*}$ & $.37 *$ & -.04 & .01 & $-.23 *$ & -.19 & $.40 * 1(.16)$ & $.37 * 1(.13)$ \\
\hline Overexcited & $.42 *$ & $.49^{*}$ & -.05 & .04 & -.11 & -.17 & $.42 * 1(.17)$ & $.49 * 1(.24)$ \\
\hline Fearful & .07 & .00 & .01 & .22 & .02 & $.23^{*}$ & - & - \\
\hline Puzzled & .12 & .19 & .10 & .16 & -.09 & -.21 & - & - \\
\hline Curious & $.41^{*}$ & $.53 *$ & -.01 & -.02 & $-.33 *$ & $-.44 *$ & $.41 * 1(.17)$ & $.53 * 1(.28)$ \\
\hline Blessed & $.55^{*}$ & $.52 *$ & -.18 & -.01 & $-.30 *$ & $-.32 *$ & $.55^{* 1}(.30)$ & $.52 * 1(.27)$ \\
\hline Flirty & $.39 *$ & $.40^{*}$ & -.04 & .08 & -.14 & -.20 & $.39 * 1(.15)$ & $.40 * 1(.16)$ \\
\hline Seduced & $.41^{*}$ & $.29 *$ & -.06 & .12 & -.14 & -.14 & $.41 * 1(.17)$ & $.29 * 1(.09)$ \\
\hline Active & $.46^{*}$ & $.52 *$ & -.11 & -.08 & $-.48 *$ & $-.48 *$ & $-.31 * 3 / .28 * 1(.28)$ & $.36 * 1 /-.27 *^{3}(.32)$ \\
\hline Schadenfreude & .02 & .02 & .01 & -.01 & .10 & .17 & - & - \\
\hline
\end{tabular}


European Journal of Humour Research1(3\&4)

\begin{tabular}{lccccccc} 
Impressed & $.47 *$ & $.33 *$ & -.01 & .05 & -.19 & -.21 & $.47 * 1(.23)$ \\
Associated & $.53 *$ & $.34 *$ & -.22 & .21 & $-.34 *$ & -.10 & $.53 * 1(.28)$ \\
Threatened & -.04 & -.12 & .09 & .19 & -.01 & .13 & - \\
Freed & $.41 *$ & $.34 *$ & -.05 & -.02 & $-.29 *$ & $-.24 *$ & $.44^{* 1}(.17)$ \\
Appreciated & $.37 *$ & $.26 *$ & .05 & .21 & $-.24 *$ & $-.25 *$ & $\left..34^{*}\right)$ \\
\hline
\end{tabular}

Note. $N=113$. Coefficients of regression analysis are beta-coefficients ( $R^{2}$ in parentheses). Method of regression $=$ Stepwise. In case no variable entered the regression, no coefficients are presented (-). Indices $\left({ }^{1}\right.$ to $\left.{ }^{3}\right)$ indicate significant predictors in the regression analysis. Rise $=$ Rise above yourself; Took $=$ Took something away from it; Laughter $=$ Burst into laughter; Associated $=$ Associated with the clown; CC $=$ Circus clown; HC $=$ Hospital clown.

$* p<.05$ (Bonferroni-corrected). 
Table 3 shows that feeling exhilarated, hilarity, playful, and burst into laughter were highly correlated with state cheerfulness (STCI-S<18>). Perhaps due to the semantic overlap, these ratings exhibited high correlations, which were higher for circus clowns than for hospital clowns. To a lower extent, we also found positive relationships between state cheerfulness and most of the other positively connoted CLEM-29 ratings (i.e., those with a smaller overlap). Most ratings of the CLEM-29 were uncorrelated with state seriousness, however, for the hospital clown, feeling privileged was positively correlated with state seriousness. State bad mood was negatively correlated with some ratings from the CLEM-29 (e.g., exhilarated, active), and positively correlated with feeling confused, creepy, and fearful. Results of the regression analyses indicated four different types of relationships between the CLEM-29 ratings and the STCI-S scales: A majority of CLEM-29 ratings, especially the ratings referring to a humorous state, was solely predicted by (positive) state cheerfulness. Certain ratings were represented in the humour-related mood model as a combination of (positive) state cheerfulness and (positive) state seriousness (e.g., touched, privileged, took something away from it, imaginative, appreciated, associated with the clown, playful). These seem to be the states requiring a cheerful mood and a more serious frame of mind (i.e., a contemplative rather than silly cheerful state). A group of ratings was predicted by state bad mood only (e.g., confused, creepy), and active is predicted by (low) bad mood and high state cheerfulness. While state cheerfulness, state seriousness, and state bad mood seem to mediate the effects of the clowns on the various facets of positive and negative experiences, the inspection of explained variance suggests that for most of the ratings, the variance in the CLEM-29 ratings cannot fully be explained through these three states.

In sum, the inspection of the relationships of the clown-specific CLEM-29 ratings with two models of emotional states showed that some aspects of experience induced by clowns are already incorporated well in existing models of emotional states. This is especially true for experiences that describe a positive state characterized by cheerfulness and hilarity. While these are well represented in two models, several other clown-specific experiences and judgments are not sufficiently covered.

\subsubsection{Prediction of the global feelings towards the videos}

Next, the prediction of the global positive and negative feelings experienced by participants while watching the videos was examined. More precisely, it was tested whether some of the clown specific ratings meaningfully contributed to the prediction after controlling for age, gender and the general mood scales. Therefore, hierarchical multiple regression analyses with age, gender (block 1, method: enter), the BSKE (EWL)-scales (block 2, stepwise), the STCI-S <18> scales (block 3, stepwise), and the CLEM-29 ratings as predictors (block 4, stepwise), and the positive and negative global experiences towards the videos as criteria (separately for both types of clowns) were conducted. Results are displayed in Table 4. All regressions consisted of more than one step, but only results of the final step are given. 
Table 4. Final Steps of Hierarchical Multiple Regression Analyses predicting Global Positive and Negative Experiences towards the Clown Videos

\begin{tabular}{|c|c|c|c|c|c|}
\hline Positive Experiences & $\beta$ & $\mathrm{R}$ & Negative Experiences & $\beta$ & $\mathrm{R}$ \\
\hline Circus Clown & & & Circus Clown & & \\
\hline Age & -.11 & & Age & $.23 * *$ & \\
\hline Gender & $.17 *$ & & Gender & -.11 & \\
\hline Cheerfulness $^{1}$ & -.12 & & Irritation $^{1}$ & .11 & \\
\hline State cheerfulness ${ }^{2}$ & $.40^{* *}$ & & State cheerfulness ${ }^{2}$ & $-.27 *$ & \\
\hline \multirow[t]{3}{*}{ Associated with the clown ${ }^{3}$} & $.32 * *$ & .63 & Confused $^{3}$ & $.23 *$ & \\
\hline & & & Active $^{3}$ & $.30 * *$ & \\
\hline & & & Associated with the clown ${ }^{3}$ & $-.29 * *$ & .60 \\
\hline
\end{tabular}

Hospital Clown

Age

Gender

Vigour $^{1}$

Anxiety/sadness ${ }^{1}$

Associated with the clown ${ }^{3}$

Privileged $^{3}$

Touched $^{3}$

Imaginative ${ }^{3}$

Seduced $^{3}$

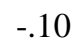

$-.11$

$.23^{*}$

$.23 * *$

$.57 * * *$

$-.27 * *$

$.19^{*}$

$-.24 *$

$.18^{*}$
Hospital Clown

$\begin{array}{ll}\text { Age } & .04\end{array}$

Gender $\quad .16^{*}$

Irritation $^{1} \quad .36^{* * *}$

Associated with the clown ${ }^{3} \quad-.40^{* * *}$

$\begin{array}{ll}\text { Appreciated }^{3} & .38^{* * * *}\end{array}$

Note. $N=113$. Age and gender were entered using forced entry; all other predictors were entered stepwise. Indices indicate the nature of the predictors: ${ }^{1}$ BSKE $(E W L)=$ Mood Rating Inventory, ${ }^{2}$ STCI-S $\langle 18\rangle=$ StateTrait Cheerfulness Inventory, ${ }^{3}$ CLEM-29 $=29$ Clown Emotion List. Only the final step of the regression is presented. $\beta=$ Standardized coefficient beta; $R=$ Multiple correlation coefficient.

$* p<.05 . * * p<.01 . * * *<.001$.

The regression analyses (Table 4) revealed that some of the clown-specific ratings (CLEM29) showed incremental validity in the prediction of the intensity of global positive and negative feelings towards the videos over and above the global and the humour-related state scales. The prediction of positive experiences towards the circus clown video emerged in four steps $\left(R^{2}=.40\right.$ in the final step). Male gender, a cheerful state, and the feeling of a close association to the clown predicted the intensity of positive feelings towards the circus clown video. The CLEM-29 rating feeling associated with the clown contributed an additional $8 \%$ of explained variance to the prediction of the positive experiences towards the circus clown video. As regards the prediction of the intensity of negative experiences towards the circus clown, again (low) cheerfulness and the feeling of connectedness to the clown played a role, combined with higher age, and the feeling of confusion and activeness (six steps; $R^{2}=.36$ in the final step) Here, the incremental contribution of the CLEM-29 rating feeling associated with the clown to the prediction of the negative global experience was $6 \%$.

The prediction of the positive experiences towards the hospital clown video emerged in eight steps. Feeling vigorous, anxious/sad, associated with the clown, privileged, touched, imaginative, and seduced predicted the positive experiences towards the video clip $\left(R^{2}=.47\right.$ in the final step). Variables related to amusement did not enter the prediction, but this does 
not necessarily mean that they do not play a role. The zero-order correlations between the positive experiences towards the video and variables representing a state of amusement (e.g., state cheerfulness) were all positive (all $r$ between .22 and .30 , all $p<.05$ ). However, the relations to the clown-specific ratings exceeding amusement were numerically higher (e.g., touched: $r=.41, p<.01$ ). Those ratings (associated with the clown, privileged, touched, imaginative, seduced) contributed an incremental $32 \%$ of explained variance to the prediction of the positive experiences towards the hospital clown video. Interestingly, those ratings were represented in the humour-related mood model of emotional states as a combination of state cheerfulness and seriousness (see Table 3). This indicates that the positive experiences towards the hospital clown video might best be predicted by a more profound cheerful mood combined with a serious state of mind. A separate regression analysis predicting the positive experiences towards the clown videos only with the scales of the STCI-S $<18>$ as predictors (method: stepwise) supported this notion. The liking of the hospital clown video was predicted by state cheerfulness $(\beta=.28, p<.01)$ and state seriousness $(\beta=.20, p<.05$; $\left.R^{2}=.09\right)$. On the other hand, the circus clown video was predicted by cheerfulness only $\left(\beta=.50, p<.001, R^{2}=.25\right)$. As regards the negative experiences towards the hospital clown video, male gender, irritation, low association with the clown, and appreciation predicted the intensity of negative feelings towards the hospital clown video (four steps, $R^{2}=.34$ in the final step). Those ratings (feeling associated with the clown, feeling appreciated) contributed an additional $20 \%$ of explained variance to the prediction of the negative experiences towards the hospital clown video.

In sum, results of the regression analyses revealed that the global experiences towards the circus clown video was predicted by a cheerful state combined with a close connection to the clown. The hospital clown video was predicted mainly by clown-specific emotion ratings relating to feelings that can be expressed as a profound and contemplative cheerful state and closeness to the clown.

\subsection{Discussion}

Study 1 tested to what extent the clown-specific adjectives and short phrases relate to already existing instruments for the assessment of emotional states (i.e., criterion one), and to what extent they predict a global evaluation of the positive and negative feelings towards the clowns (i.e., criterion two). As expected, we found some empirical overlap between general models of mood, meaning that certain CLEM-29 ratings correlated positively with a state of relaxed elation, cheerfulness and vigour, and negatively with deactivation and bad mood. This fits well into the study of humorous stimuli and resulting exhilaration (Ruch 1993), suggesting that watching clowns either performing on stage or interacting with people in need of care induces a state of pleasurable, relaxed excitation.

However, also in line with our expectations, it was mostly the cheerfulness and hilarity elements of the clown-specific list that showed some degree of redundancy with existing scales of emotional states, but other emotional qualities like feeling connected to the clown, feeling touched or elevated did not relate strongly to general models of emotional states (and thus represent a unique quality). It should be highlighted that for the hospital clown, feeling touched, imaginative, playful, associated with the clown, and appreciated were predicted by both cheerfulness and seriousness. It seems that a cheerful mood and a serious frame of mind together produce states that seem to be a more profound form of cheerfulness, rather than superficial and shallow. Furthermore, those ratings were good predictors for the intensity of global positive feelings towards the hospital clown video. In particular, the more people felt associated with the clown, the higher was their intensity of positive feelings towards the video clip, and the less associated they felt with the clown, the higher was their intensity of negative feelings towards the video clip. 
It should be noted that the results of the regression analyses are more of an exploratory nature, and although some of the clown-specific ratings played a role in predicting the global experiences towards the videos, those not entering the regression should not be discarded from the list for several reasons: The criterion consisted of a single rating of limited reliability rather than a scale. Also, an examination of the descriptive statistics of the positive experiences towards the hospital clown video $(M=4.99, S D=1.47$; scale from 1 to 7$)$ revealed that it was negatively skewed. Furthermore, due to the high number of predictors and the relatively small sample size one should be cautious about an over-interpretation of the results of the regression.

Nevertheless, Study 1 indicates that there is more to seeing clowns than covered by a general model of positive affectivity (including elation, vigour), and by a humour-related model of mood (cheerfulness, seriousness, and bad mood). This study gives a first impression on the importance of the clown-specific emotional states compared to general mood states when watching videos of clowning. All in all, it seems that certain ratings of the CLEM-29 are useful in predicting the appreciation of a hospital clown scene over and above the general and humour-related states.

However, this study included only one hospital clown scene among a range of possible interventions. Although all belong to the same group of professionals, it is likely that they differ in style, performance, and clown persona. These differences might lead to different emotions elicited in observers and patients. For example, a more calm and serious clown who triggers feelings that exceed amusement (e.g., feeling appreciated), might not fit to every individual, as some individuals prefer more outward directed hilarity and fun. In the next study, it is aimed to include a greater variety of videos of clown-interactions, and to present these to a larger sample. It is suggested that some of the clown-specific ratings will be elicited in any hospital clown intervention, as they are of a more general type (e.g., exhilaration, surprise, hilarity). Furthermore, the expert clowns indicated that these emotional states have been elicited in a great variety of situations they have been part of. Other ratings are more specific to certain clowns or certain situations, and thusly might not be elicited by all clowns (e.g., flirtatiousness, touch).

Furthermore, this study did not examine the unique contribution of these ratings in the evaluation of hospital clown interventions compared to other possible interventions. It was suggested that hospital clowns add a unique component to the hospital routine, which lies in the combination of attributes of amusing circus clowns and empathic nurses. So in Study 2, we investigate the emotional experiences elicited by watching videos of hospital clowns in comparison to videos of two other groups of professionals: nurses and circus clowns.

\section{Study 2}

The third criterion for the usefulness of a rating stated that if one can expect a difference between the groups of professionals (e.g., a hospital clown is more exhilarating than a nurse), the results actually should demonstrate this expected difference for this item (i.e., the rating should be higher for the hospital clown than for the nurse). Study 2 further investigates the usefulness of the clown-specific ratings (CLEM-29) in the evaluation of hospital clown interventions applying criterion three and also including all videos from the CEVC. It will therefore be examined whether watching hospital clowns, circus clowns and empathic nurses results in different emotional responses in observers. It is hypothesized that both kinds of clowns elicit feelings of amusement. Furthermore, hospital clowns are expected to elicit feelings exceeding amusement. The nurse is expected to share the empathic, but not the amusing component with the hospital clown. It is expected that the nurse and the circus clown share the least qualities, and hence, will elicit very different emotional responses in observers. 
In Study 2, it will also be of interest to see how unique vs. redundant a particular rating of the CLEM-29 is, that is, how strongly it correlates with other ratings. Such clusters of correlating ratings can be identified by factor analysis. This can help to either combine some ratings to a scale or dimension, or to avoid redundancies by searching for ratings with low intercorrelations. It should be highlighted that the unique ratings are still of interest and importance, especially if they are sensitive to differences among the three groups.

\subsection{Method}

\subsubsection{Participants}

The sample consisted of 183 German-speaking adults (26.8\% male) in the ages from 18 years to 63 years $(M=28.50 ; S D=9.31)$, and was a mixed sample of students and well-educated adults. Participants were recruited in a multitude of ways, for example via mailing lists, flyers or in undergraduate psychology seminars. Initially 226 adults participated in the study, but an inspection of the response pattern for each participant over all clown ratings $(M=2.50$, $S D=0.80$ ) led to the exclusion of 43 participants, whose means were below one standard deviation of the overall mean (i.e., below $M=1.70$ ).

\subsubsection{Instruments}

The 29 Clown Emotion List (CLEM-29; Auerbach et al. 2012a) as described in section 3.2 was used to assess clown-specific emotional states.

The Cheerfulness-Empathy Video Collection (CEVC, Auerbach et al. 2012b) as described in section 3.1. was used in Study 2 including all 15 video clips. To test the internal consistency of each set of five videos, we calculated reliability coefficients (Cronbach's alpha). This was done for all CLEM-29 ratings. For the circus clown videos, the median alpha of 29 ratings was .78. For the nurse videos, the median alpha was .74. And for the hospital clown, the median alpha was .80 .

\subsubsection{Procedure}

Participants were presented the 15 video clips from the CEVC in random order. They were instructed to watch each clip, and to rate their emotional state on the 29 ratings of the CLEM29 after each clip. The study was conducted via an online data collection program (www.unipark.de). The participation was voluntary, and psychology students participated in exchange for course credit.

\subsection{Results}

\subsubsection{Dimensionality of the CLEM-29}

About nine percent of the ratings correlated highly (70 out of 812 possible intercorrelations over all clowns were above .70) and this raised the question of redundancy of the ratings. Therefore the emotional responses elicited by the ten clown videos were factor analysed. To arrive at one score for each participant for each of the CLEM-29 ratings, the mean of each rating was computed by averaging across the five clips for circus and hospital clown videos separately. As the factors should be valid for both types of clowns, the two matrices were merged into one by using two lines for each participant, one for the 29 ratings for circus clowns and the others formed by the 29 hospital clown ratings. The intercorrelations among the 29 ratings across the $N=366$ data points were subjected to a principal components analysis. Four eigenvalues exceeded unity, and also the scree test and parallel analysis by Horn suggested the retention of four factors (the first six eigenvalues were 12.70, 4.07, 2.51. $1.68,0.92$, and 0.72 ). Four factors explaining $72.33 \%$ of the variance were extracted and rotated to the Oblimin criterion. The oblique factor solution is given in Table 5. 
Table 5. Factor Pattern Matrix for Oblimin Four Factor Solution for the CLEM-29 Ratings

\begin{tabular}{|c|c|c|c|c|c|}
\hline & $\mathrm{F} 1$ & $\mathrm{~F} 2$ & $\mathrm{~F} 3$ & $\mathrm{~F} 4$ & $h^{2}$ \\
\hline Speechless & .18 & .38 & .58 & .16 & .60 \\
\hline Touched & .46 & -.09 & .65 & .05 & .76 \\
\hline Surprised & -.01 & .29 & .22 & .74 & .74 \\
\hline Laughter & -.21 & -.09 & -.04 & .93 & .70 \\
\hline Confused & -.09 & .74 & -.13 & .15 & .62 \\
\hline Exhilarated & .14 & -.18 & .04 & .82 & .77 \\
\hline Rise & .86 & .08 & .09 & -.02 & .77 \\
\hline Privileged & .86 & .03 & .21 & -.10 & .77 \\
\hline Elevated & .82 & -.02 & .00 & -.02 & .65 \\
\hline Creepy & .03 & .86 & -.10 & -.20 & .73 \\
\hline Took & .73 & -.04 & .25 & .11 & .75 \\
\hline Imaginative & .45 & .05 & -.15 & .51 & .72 \\
\hline Playful & .44 & -.04 & -.25 & .55 & .76 \\
\hline Hilarity & .09 & -.11 & -.06 & .88 & .83 \\
\hline Naughty & .35 & .18 & -.42 & .46 & .74 \\
\hline Overexcited & .17 & .31 & -.52 & .44 & .76 \\
\hline Fearful & -.06 & .86 & .17 & -.08 & .71 \\
\hline Puzzled & .17 & .43 & .22 & .51 & .71 \\
\hline Curious & .45 & .09 & .14 & .46 & .69 \\
\hline Blessed & .80 & -.09 & .18 & .02 & .71 \\
\hline Flirty & .81 & .09 & -.39 & .04 & .77 \\
\hline Seduced & .82 & .03 & -.26 & -.02 & .66 \\
\hline Active & .81 & .05 & -.10 & .02 & .68 \\
\hline Schadenfreude & .08 & .43 & -.49 & .23 & .58 \\
\hline Impressed & .34 & .04 & .47 & .47 & .78 \\
\hline Associated & .57 & -.07 & .46 & .17 & .74 \\
\hline Threatened & -.01 & .89 & .04 & -.09 & .76 \\
\hline Freed & .81 & -.07 & -.03 & .14 & .77 \\
\hline Appreciated & .83 & -.07 & .19 & .00 & .76 \\
\hline
\end{tabular}

Note. $N=$ 366. Extraction: Principal component analysis. Rotation: Oblimin. Boldface indicates highest factor loadings in a row. Rise = Rise above yourself; Took = Took something away from it; Laughter = Burst into laughter; Associated $=$ Associated with the clown. F1 = Transcendence; F2 = Uneasiness; F3 = Arousal; F4 = Amusement; $h^{2}=$ communality.

Table 5 shows two major and two minor factors in terms of explained variance. The factors are placed in a two-dimensional space of valence (positive, negative) and arousal (low, high), and all four factors are represented (total variance explained: $72.33 \%$ ). A potent first factor (explaining $43.80 \%$ of the variance) was loaded by the eleven ratings, all of which have a positive valence (in descending order): privileged, rise above yourself, appreciated, elevated, seduced, active, freed, flirty, blessed, took something away from it, and associated with the clown. These ratings describe the recipients being uplifted and surpassing the ordinary, and 
hence the factor was tentatively labelled transcendence, according to its non-religious connotation (Merriam-Webster's Online Dictionary 2012). The second factor was loaded by four ratings (in descending order): threatened, fearful, creepy, and confused. It refers to the level of negative feelings induced by clowns, and is therefore called uneasiness. The third factor was bipolar and was loaded by the four ratings (in descending order): touched, speechless (both positively), overexcited, and schadenfreude (both negatively). All ratings of this factor relate to different states of arousal, in which positive loadings (touched and speechless) refer to a calm state, that is, low arousal, whereas negative loadings (overexcited and schadenfreude) refer to a more heightened arousal. The factor was labelled low vs. high arousal (short: arousal). All ratings on arousal showed substantial second loadings (above .30) on the valence dimensions. The rating overexcited had positive secondary loadings on amusement and uneasiness. The ratings of schadenfreude and speechless had positive second loadings on uneasiness. Feeling touched loaded positively on transcendence.

Factor four was also a potent factor and was loaded by nine ratings (in descending order): burst into laughter, hilarity, exhilarated, surprised, playful, imaginative, puzzled, curious, and naughty. Factor four merged a variety of amusement-related states (including more calm cheerfulness and aroused hilarity) and was tentatively labelled amusement. The rating impressed loaded equally high and positively on amusement and arousal. As impressed is primarily neutral, and can be used in a positive or negative context, it was assigned to the arousal factor. Moreover, the amusement-ratings imaginative, playful, naughty, curious, and additionally impressed showed positive second loadings above .30 on transcendence. Feeling puzzled showed a positive second loading on uneasiness. Flirty, naughty and schadenfreude both loaded negatively on arousal, and associated with the clowns loaded positively on arousal.

In sum, the results of the principal component analysis suggested the need of at least four factors to understand the structure of the CLEM-29 ratings. All factors except transcendence and amusement $(r=.52)$ correlated only slightly (between $r=-.04$ and .20 ). Communalities indicated the explanation of more than $50 \%$ of the variance for each rating. Other solutions including more than four factors might be considered to account for all reliable variance. An alternative view is that there are the two major core aspects of clown interactions, namely amusement (as felt for both observer and actor, and both hospital clown and circus clown) and transcendence (probably more prevalent in the observer, and more typical for hospital clowns), and then some more unique and narrow stylistic aspects of clown behaviour and interaction.

\subsubsection{Differences between circus clowns, nurses and hospital clowns}

To examine the differences in elicited emotions between different groups of professionals (i.e., criterion three), ratings for the videos depicting hospital clowns, circus clowns and nurses were analysed. Repeated measures ANOVAs with video clip (circus clown, nurse, hospital clown) as repeated measurement factor were computed for the four factors (based on the factor scores that were estimated using the regression method) and for all 29 individual ratings. Again, each CLEM-29 rating was aggregated across the five clips for circus clown, nurse, and hospital clown videos. Post-hoc tests (Bonferroni corrected) were applied to test between which of the groups a difference occurred. The results are displayed in Table 6. For conceptual reasons, results of each factor are presented first (depicting the general pattern), followed by the results of each rating belonging to the respective factor. The latter will only be discussed in more detail when deviating from the general pattern. 
European Journal of Humour Research1(3\&4)

Table 6. Descriptive Statistics and Results of ANOVAs with aggregated video clips for Circus Clown, Nurse, Hospital Clown (CLEM-29 Ratings and 4 Factors)

\begin{tabular}{|c|c|c|c|c|c|c|c|c|}
\hline \multirow[b]{2}{*}{ Factor/Rating } & \multicolumn{2}{|c|}{ Circus clown } & \multicolumn{2}{|c|}{ Nurse } & \multicolumn{2}{|c|}{ Hospital clown } & \multirow[b]{2}{*}{$F(2,364)$} & \multirow[b]{2}{*}{ partial $\eta^{2}$} \\
\hline & $M$ & $S D$ & $M$ & $S D$ & $M$ & $S D$ & & \\
\hline Transcendence & $-0.46 c$ & 0.73 & $-0.33 b$ & 0.61 & $0.46 a$ & 1.02 & $181.92 *$ & .50 \\
\hline Associated & $2.10 \mathrm{c}$ & 1.00 & $3.16 \mathrm{~b}$ & 1.24 & $4.09 \mathrm{a}$ & 1.37 & $225.77 *$ & .55 \\
\hline Appreciated & $1.95 \mathrm{c}$ & 1.04 & $3.06 \mathrm{~b}$ & 1.44 & $3.86 a$ & 1.57 & $226.15^{*}$ & .55 \\
\hline Blessed & $1.57 \mathrm{c}$ & 0.77 & $1.85 \mathrm{~b}$ & 0.97 & $2.77 \mathrm{a}$ & 1.36 & $135.08 *$ & .43 \\
\hline Privileged & $1.63 c$ & 0.88 & $2.54 b$ & 1.27 & $2.98 \mathrm{a}$ & 1.49 & $116.73 *$ & .39 \\
\hline Took & $1.98 \mathrm{c}$ & 1.00 & $2.37 \mathrm{~b}$ & 1.09 & $3.35 \mathrm{a}$ & 1.41 & $115.39 *$ & .39 \\
\hline Freed & $1.89 \mathrm{~b}$ & 0.97 & $1.62 \mathrm{c}$ & 0.79 & $2.71 \mathrm{a}$ & 1.36 & $99.26 *$ & .35 \\
\hline Elevated & $1.78 \mathrm{~b}$ & 0.99 & $1.67 \mathrm{~b}$ & 0.86 & $2.61 \mathrm{a}$ & 1.43 & $89.36 *$ & .32 \\
\hline Rise & $1.67 \mathrm{~b}$ & 0.89 & $1.82 \mathrm{~b}$ & 0.88 & $2.53 \mathrm{a}$ & 1.26 & $82.00 *$ & .31 \\
\hline Seduced & $1.53 b$ & 0.83 & $1.17 \mathrm{c}$ & 0.41 & $1.99 \mathrm{a}$ & 1.22 & $81.88 *$ & .31 \\
\hline Flirty & $1.70 \mathrm{~b}$ & 0.93 & $1.23 \mathrm{c}$ & 0.44 & $1.97 \mathrm{a}$ & 1.09 & $79.76^{*}$ & .31 \\
\hline Active & $1.98 \mathrm{~b}$ & 1.05 & $1.98 b$ & 0.96 & $2.74 \mathrm{a}$ & 1.35 & $56.61 *$ & .24 \\
\hline Uneasiness & $0.20 \mathrm{a}$ & 1.13 & $0.42 \mathrm{a}$ & 1.22 & $-0.20 b$ & 0.80 & $31.48 *$ & .15 \\
\hline Confused & $2.27 \mathrm{a}$ & 1.10 & $1.73 b$ & 0.76 & $1.67 \mathrm{~b}$ & 0.76 & $45.51^{*}$ & .20 \\
\hline Fearful & $1.34 \mathrm{~b}$ & 0.60 & $1.82 \mathrm{a}$ & 0.91 & $1.33 b$ & 0.55 & $43.64 *$ & .19 \\
\hline Threatened & $1.38 \mathrm{~b}$ & 0.62 & $1.68 \mathrm{a}$ & 0.88 & $1.23 c$ & 0.42 & $33.52 *$ & .16 \\
\hline Creepy & $1.65 \mathrm{a}$ & 0.78 & $1.67 \mathrm{a}$ & 0.85 & $1.34 \mathrm{~b}$ & 0.56 & $19.24^{*}$ & .10 \\
\hline Arousal & $-0.66 c$ & 0.73 & $0.89 \mathrm{a}$ & 0.72 & $0.66 b$ & 0.77 & $363.55^{*}$ & .67 \\
\hline Touched & $1.27 \mathrm{c}$ & 0.51 & $2.59 \mathrm{~b}$ & 1.07 & $3.45 \mathrm{a}$ & 1.23 & $360.99 *$ & .67 \\
\hline Overexcited & $2.86 \mathrm{a}$ & 1.49 & $1.25 \mathrm{c}$ & 0.42 & $1.97 \mathrm{~b}$ & 0.91 & $179.83 *$ & .50 \\
\hline Impressed & $2.54 \mathrm{c}$ & 1.14 & $3.05 b$ & 1.26 & $3.77 \mathrm{a}$ & 1.31 & $90.72 *$ & .33 \\
\hline Schadenfreude & $1.62 \mathrm{a}$ & 0.86 & $1.05 \mathrm{c}$ & 0.16 & $1.13 b$ & 0.31 & $84.61 *$ & .32 \\
\hline Speechless & $2.07 \mathrm{c}$ & 1.03 & $2.47 \mathrm{~b}$ & 1.02 & $2.87 \mathrm{a}$ & 1.10 & $55.66^{*}$ & .23 \\
\hline Amusement & $0.00 \mathrm{a}$ & 1.11 & $-1.54 b$ & 0.56 & $0.00 \mathrm{a}$ & 0.88 & $337.50 *$ & .65 \\
\hline Hilarity & $3.35 \mathrm{a}$ & 1.20 & $1.53 b$ & 0.62 & $3.44 \mathrm{a}$ & 1.09 & $346.22 *$ & .66 \\
\hline Exhilarated & $3.48 b$ & 1.21 & $1.85 \mathrm{c}$ & 0.75 & $3.89 \mathrm{a}$ & 1.04 & $314.43 *$ & .63 \\
\hline Playful & $3.28 b$ & 1.36 & $1.54 \mathrm{c}$ & 0.66 & $3.51 \mathrm{a}$ & 1.37 & $304.37 *$ & .63 \\
\hline Laughter & $2.97 \mathrm{a}$ & 1.21 & $1.26 \mathrm{c}$ & 0.42 & $2.66 \mathrm{~b}$ & 1.03 & $245.76^{*}$ & .58 \\
\hline Imaginative & $3.01 \mathrm{~b}$ & 1.31 & $1.50 \mathrm{c}$ & 0.66 & $3.22 \mathrm{a}$ & 1.37 & $254.53 *$ & .58 \\
\hline Naughty & $2.77 \mathrm{a}$ & 1.29 & $1.32 \mathrm{c}$ & 0.51 & $2.55 b$ & 1.11 & $199.21 *$ & .52 \\
\hline Surprised & $3.10 \mathrm{a}$ & 1.16 & $2.21 \mathrm{~b}$ & 0.95 & $3.15 \mathrm{a}$ & 1.16 & $82.90^{*}$ & .31 \\
\hline Curious & $2.57 \mathrm{~b}$ & 1.17 & $2.44 b$ & 1.14 & $3.27 \mathrm{a}$ & 1.28 & $62.79 *$ & .26 \\
\hline Puzzled & $2.55 b$ & 1.12 & $2.26 \mathrm{c}$ & 1.04 & $2.79 \mathrm{a}$ & 1.12 & $25.32 *$ & .12 \\
\hline
\end{tabular}

Note. $N=183$. Ratings are sorted according to highest effect size within one factor. Factor scores are estimated using the regression method. Rise $=$ Rise above yourself; Took $=$ Took something away from it; Laughter $=$ Burst into laughter; Associated = Associated with the clown. $M=$ mean, $S D=$ standard deviation. Partial $\eta^{2}=$ effect size.

$* p<.001$.

$\mathrm{a}>\mathrm{b}>\mathrm{c}$ indicate significant results of pairwise comparisons (Bonferroni-corrected) 
Table 6 shows that all the main effects for the broader factors and the single ratings were significant. The effect sizes (partial $\eta^{2}$ ) ranged from .10 to .67 indicating large effects (Tabachnick and Fidell 2013). Regarding the factor of transcendence, the post hoc test showed that the hospital clowns led to highest feelings of transcendence, followed by the nurses which, in turn, were higher than the circus clowns. At the rating level the emotional responses to the three types of videos showed that five of the ratings loaded on the transcendence factor followed the same pattern as the factor: Compared to the nurse, the hospital clown made people feel more privileged, appreciated, and blessed, and they feel they took something away from it, and feel associated with the clown. They also reported to feel more touched, speechless [both factor arousal], and impressed [factor arousal]). All other ratings loading on transcendence, that is, active, rise above yourself, and elevated (as well as curious stemming from the factor amusement) followed a similar pattern: The hospital clown (alone or shared with others) elicited more intense emotional responses compared to both the nurse and circus clown videos, while the latter two did not differ. Furthermore, the hospital clown made people feel more seduced, freed, and flirty than the circus clown. In these ratings, the circus clown elicited higher responses than the nurse.

Regarding the factor of amusement, the post hoc test showed that videos of both hospital clown and circus clown elicited the same level of amusement. Both led to higher feelings of amusement than the nurse videos. Looking at differences in more detail, the ratings for hilarity and surprised loaded on amusement and were in line with the pattern of the factor. The hospital clown exceeded the circus clown in the ratings exhilarated, playful, imaginative and puzzled. Again, the video of the nurse elicited lowest ratings. On the other hand, the circus clown yielded higher ratings for naughty and burst into laughter than the hospital clown, which, in turn, did more so than the nurse. Finally, the hospital clown elicited higher ratings for curiosity than the nurse and the circus clown, which did not differ in the responses elicited.

Next, the factor of arousal was investigated. On the positive pole, indicating low arousal, the pattern was equal to the transcendence factor: the hospital clown elicited the highest feelings of touched, speechless, and impressed, followed by the nurse, and last by the circus clown. On the negative pole, indicating a state of high arousal, the circus clown led to the highest feelings of overexcitement and schadenfreude, followed by the hospital clown and last by the nurse. This pattern was equal to the pattern of the amusement-ratings burst into laughter and naughty.

Although means for negatively connoted ratings (e.g., fearful, creepy) were rated generally low (see Table 6), differences between the groups were identified. The factor of uneasiness presented a distinct pattern: Both nurse videos and circus clown videos elicited higher levels of uneasiness than the hospital clown. At the level of single ratings, both the videos of nurses and circus clowns elicited higher feelings of creepy than the hospital clown. The nurse videos elicited the highest feelings of uneasiness in three ratings. Participants reported higher levels of felt threat in the nurse video, compared to the circus clown video, and lowest feelings of threat in the hospital clown video. The nurse video elicited higher levels of fear than videos of both circus and hospital clown. The hospital and circus clown did not differ in eliciting fear. Finally, the circus clown made people feel more confused than both nurses and circus clowns, which did not differ.

In sum, all CLEM-29 ratings (as well as the four factors) differentiated among the groups (confirming criterion three). The hospital clown videos elicited the highest ratings in 21 out of the 29 ratings, all of which referred to positive feelings of amusement and transcendence. Both hospital clown and circus clown prompted equal ratings for hilarious, but the hospital clown additionally elicited feelings of elevation and touch in observers. The nurse videos, in turn, lacked the elicitation of amusement, but obtained slightly higher levels of 
uneasiness, whereas the circus clown confused and overexcited observers most; i.e., yielded higher scores that hospital clowns and nurse.

\subsection{Discussion}

Study 2 investigated whether video clips of hospital clowns elicited different emotions than circus clowns and nurses in an online observer sample. One finding worth mentioning is the low overall level of ratings in the negative experiences and emotions, independent of the type of clown. While in the present study, observing a circus clown performing on stage or a hospital clown interacting with patients quite expectedly did not make observers feel anxious or threatened, it is still important not only to investigate positive responses to humorous interventions, but also negative ones. Firstly, an inspection of the standard deviation for the negative responses indicates that there is variation in responses, meaning that some people indeed reported feelings of uneasiness as response to the clowns. Secondly, results from qualitative studies described, albeit rare, negative reactions towards clowns in children (Kingsnorth et al. 2010, Linge 2011). Thirdly, as Ruch and Rath (1993) showed, positive (funniness/exhilaration) and negative (simple/boredom) evaluations of humorous stimuli exist independently from one another. The number of negatively connoted ratings in the CLEM-29, however, is small, due to the fact that the expert clowns mentioned only few negative reactions. However, as a limitation it needs to be acknowledged that there might be other negative feelings involved in a clown visit, which we failed to identify.

Furthermore, a limitation regarding the sample is worth mentioning. About $19 \%$ of participants were excluded from the analyses because their response pattern showed that they emotionally responded to almost none of the 15 videos, resulting in a very low overall mean for these individuals. A reason for this could be the fact that a considerable proportion of participants received course credit for participation, in combination with the long duration of the completion of the study (participants were asked to watch 15 video clips and respond to 29 items after each clip). These individuals might have dropped out otherwise, but finished instead without truthfully engaging in the task.

\subsubsection{Dimensionality of the CLEM-29}

One aim of Study 2 was to investigate the dimensionality of emotions elicited by clown videos, meaning the quantity of dimensions needed to account for the 29 adjectives and short phrases which were considered to be relevant in the context of clowning. We found four dimensions referring to the feeling of transcendence, uneasiness, arousal, and amusement, which account for three-quarters of the reliable variance in the ratings. The factorial structure, however, is complex, suggesting that some ratings need to be eliminated. Maybe also other ratings need to be added so that also the meaning of the minor factors becomes clearer. A closer inspection of the bipolar factor of arousal shows that the pattern of the positive pole mirrors the factor of transcendence, and the pattern of the negative pole some amusementratings. This bipolar factor might be a result of the heterogeneity of the two types of clowns, and some ratings might have gained a different connotation depending on the type of clown. For example, while watching a hospital clown, participants might have interpreted their speechlessness as a positive feeling state, induced by the moving and surprising work of the clown. While watching the circus clown, feeling speechless might have been closer to a feeling of confusion and irritation. As noted by Ruch and Rath (1993), the humour response includes perceptions of the feeling state as well as perceptions of the stimulus properties. It might be that for some videos, participants described their experiential level (e.g., "I feel overexcited"), but for some other videos, characteristics of the stimulus were rated ("the clown is overexcited"), although the general instruction was to rate your own feeling state on all dimensions. Within one clown category, however, most ratings showed high internal 
consistency, suggesting that the understanding of some ratings varied not across all videos, but across conditions. This might more be the case for some ratings (e.g., overexcited, speechless) than for others (e.g., exhilarated, blessed).

\subsubsection{Differences between feelings elicited by circus clowns, nurses and hospital clowns}

Study 2 finally investigated whether the ratings could discriminate between the emotional experience in response to videos of hospital clowns, nurses or circus clowns (criterion three). In line with expectations, both circus and hospital clowns embodied the humorous aspect of a clown interaction, but only the hospital clowns were able to elicit feelings of transcendence, that is, privilege and appreciation, on top of amusement. Transcendent experiences were also elicited by the nurse videos, which, as expected, were missing the humorous aspect. The hospital clowns induced feelings of bliss in observers, maybe through demonstrating how they can bring novelty (surprise) to a clearly structured environment, break with daily routines and how they give power and a sense of control to the patients (i.e., enabling them to engage in an interaction, where the focus is not on their illness, disability, and weakness, but on their strengths and fantasy). After watching hospital clown videos, observers reported very low levels of uneasiness, but higher levels of touch, appreciation and a close connection to the hospital clown. The combination of watching a hospital clown doing good things plus the amusing component in doing so might have produced the highest feelings of bliss. What Adams (2002) intuitively referred to as a combination of love as well as laughter, was also evident in the present study in the form of several ratings referring to transcendence.

As regards the humour response to humorous stimuli, Ruch and Hehl (1998) argued that the perception of jokes and cartoons varies along the three factors of incongruity-resolution, nonsense, and sexual humour. The two types of clown videos used in this study seem to differ in their use of the two structure-based types of humour. Although the clown videos were not chosen according to whether their performance was incongruity-resolution based or nonsense based, our data suggested that the two types of clowns differed in the type of humour they applied in their performance. Both circus and hospital clowns acted in incongruent ways; they playfully surprised their audience (be it in the clip or the participants of the study), which clearly is a desired response to a clown. However, the circus clown led to more confusion, a feeling that can be linked to a more nonsensical humour style. In terms of the aim of hospital clowns (to do good), it is crucial that they produce a positive state in their audience. The hospital clown does not wish to confuse people (e.g., feeling of disturbance). The results of this study underpin this aim: The hospital clown elicited high feelings of surprise, as did the circus clown, but low confusion. This fits to results of the qualitative study by Linge (2011). She identified emotional dimensions relevant to the hospital clowns work: Surprise/startle, interest/excitement, and enjoyment "without demands." We found feelings of surprise, (over-) excitement and various facets of joy (e.g., exhilaration, hilarity) in our participants' reactions.

\section{General Discussion}

Results of the two studies give an insight into the specific emotional reactions towards clowns and their effect on observers. We identified a range of different feeling states that turned out to have a distinct quality, many of which are not captured by known models of mood. These clown-specific experiences cover a variety of states relating to amusement, transcendence, arousal, and uneasiness. They help to predict the intensity of global positive and negative experiences when watching the videos of clowning. Furthermore, they distinguish between circus clowns, nurses and hospital clowns in their effect on observers. An interesting finding was that feelings of uneasiness played only a minor role in this study. One of the main contributions of this study is that it goes beyond past research in that we could identify and 
describe a great variety of emotional states elicited in observers watching hospital clown scenes.

\section{Limitations}

This research led to promising results regarding the emotional experiences elicited in observers by a hospital clown in comparison to a circus clown or a nurse. Nevertheless, more studies are needed that more precisely and comprehensively describe positive and negative effects a clown intervention could have. In our studies, adult non-patient individuals watched clowning and nursing video clips. It has yet to be shown whether the same emotional responses can be found in more representative samples, as well as in clinical settings, that is, among people in need of care. The limitation within the present samples with respect to age and education is that many participants were rather young, students or former students with an academic degree.

Furthermore, more mood-influencing factors should be taken into account in an in vivo study. For example, the personality of the patient (e.g., trait cheerful vs. serious individuals), factors regarding the health issue of the patient (e.g., pain, drug influence), humour characteristics of the clown, but also factors regarding relatives and staff (e.g., acceptance of the clown intervention, support) need to be studied more closely.

Also, it is not clear yet whether the present list of adjectives and short phrases is the final list of all relevant emotional states in the context of clown visits. This list was compiled with the help of laypersons watching clowning videos, and with expert clown interviews. Asking hospital clowns what they think they elicit in the patients has advantages and disadvantages. On the one hand, these clowns are directly involved in the interventions on a regular basis, and can draw from many years of experience. They observe the immediate responses of patients and visitors (e.g., smiling and laughter), they talk to relatives and staff, and they share their knowledge and experiences with other clowns. On the other hand, their perception might be biased in that they are not objective observers of the situation, but participating observers, and might concentrate more on the positive reactions, leaving out possible negative side effects. Also, they can only report what they see or hear, but there might be a whole range of other emotions elicited, which the patients do not or cannot report (e.g., children, or adults with dementia). All in all, it cannot be ruled out that our expert clowns were reporting their subjective views that would not be fully shared by others. In a second step, it will be important to also ask patients directly involved in such a situation about their emotional reactions.

Hospital clowns do not only work with adult patients, but also with children and adolescents. It needs to be verified that all dimensions play a role at young age already, and whether the visit of a clown has the same impact on an adult patient as on a child. As Costa Fernandes and Arriaga (2010) showed, the effect of a clown accompanying a child in a preoperative phase was different for different age groups. It might be that at young age the amusing aspect and distraction have priority, and feelings of privilege, appreciation or seduction only become more important in adulthood. Also it is still unclear whether the absence of uneasiness while watching a hospital clown performance is only due to a methodological artefact (i.e., no real interaction with a clown equal no need to worry), and could emerge in an in vivo situation, or whether hospital clowns in adulthood indeed do not elicit negative feelings.

\section{Implications for future research}


Future research should focus on identifying all relevant domains of experiences that play a role in the reaction of observers and patients to a hospital clown, and have a closer look at the dimensionality (i.e., the factorial structure) of these adjectives and short phrases in other observational as well as in real clown intervention studies. Furthermore, the results presented in this research should gain more validation by including data other than self-report. It is of interest whether the observed rise in a variety of positive emotions to a hospital clown compared to a circus clown or nurse is visible on other levels, for example, they should be validated by indicating changes verified in face, body language, and later actions of patients. At a behavioural level, they could be observed by analysing the facial expressions of patients in such an intervention to distinguish smiles and laughter that occur due to the truly felt emotion of joy (i.e., the Duchenne display; e.g., Platt et al. 2013) from a fake or masking smile that could occur out of politeness or learned social rules, or out of the attempt to cover uneasiness. This could help to train clowns by fostering their awareness to different behaviours, causing differences to the response profiles induced.

Also it might be of interest whether there are individual differences in the clown as well as in the patients that lead to a different emotional quality in the clown-patient interaction, and are accompanied by a greater (or smaller) benefit for the well-being of the patient. One could argue that rather humourless (e.g., overly serious) persons, or people who dislike or fear clowns, do not benefit as much from a clown visit than, for example, more humorous and cheerful persons. On the other hand, the type of humour the clown performs might or might not match the type of humour the patient appreciates. So, the clown-patient fit regarding the humour preferences and the humorous temperament is worth investigating.

In conclusion, the present research gives a first overview on the complexity of emotional reactions induced by clowns. Existing research in the context of hospital clown interventions and their effect on patient's well-being has underestimated the variety of emotional states that play a role in the context of the evaluation of hospital clowns.

Acknowledgement. The authors would like to thank the Rote Nasen Clowndoctors Austria and Marcel Briand for their valuable help in this research.

\section{Notes}

* Address correspondence to Sarah Auerbach, Personality and Assessment, Department of Psychology, University of Zurich, Binzmuehlestrasse 14 / Box 7, 8050 Zurich, Switzerland, E-mail: s.auerbach [at] psychologie.uzh.ch

[1] The German terms were: sprachlos, gerührt, überrascht, als könnte ich loslachen, verwirrt, erheitert, über mich hinausgewachsen, privilegiert/auserwählt/besonders, erhöht, unheimlich, beschenkt, voller Phantasie, verspielt, belustigt/lustig, frech/neckisch, überdreht, furchtsam, verwundert/erstaunt, neugierig, selig, kokett, verführt, lebendig/aktiv, schadenfroh, beeindruckt, verbunden mit dem Clown/mit der Pflegeperson, bedroht, befreit, wertgeschätzt.

[2] It is noteworthy that, although a scale called cheerfulness is represented in both the BSKE (EWL) and the STCI-S $\langle 18\rangle$, it does not stand for the same construct. In the BSKE (EWL), cheerfulness (German: Gutgestimmtheit) represents a broad state of elation, composed of joy, emotional well-being and cheerfulness. On the other hand, the state cheerfulness scale (German: Heiterkeit) from the STCI$\mathrm{S}<18>$ is hierarchically lower and is composed of a more narrow state of hilarity and cheerfulness.

\section{References}

Adams, P. (2002). Humour and love: The origination of clown therapy. Postgraduate Medicine Journal, 78, 447-448. 
Auerbach, S., Hofmann, J., Platt, T., \& Ruch, W. (2012a). The 29 Clown Emotion List (CLEM-29). Unpublished research instrument, University of Zurich, Switzerland.

Auerbach, S., Hofmann, J., Platt, T., \& Ruch, W. (2012b). The Cheerfulness-Empathy Video Collection (CEVC). Unpublished research instrument, University of Zurich, Switzerland.

Bertini, M., Isola, E., Paolone, G., \& Curcio, G. (2011). Clowns benefit children hospitalized for respiratory pathologies. Evidence-Based Complementary and Alternative Medicine, 2011, 1-9.

Brutsche, M. H., Gossmann, P., Müller, R. E., Wiegand, J., Pello, Baty, F., \& Ruch, W. (2008). Impact of laughter on air trapping in severe chronic obstructive lung disease. International Journal of COPD, 3, 185-192.

Costa Fernandes, S., \& Arriaga, P. (2010). The effects of clown intervention on worries and emotional responses in children undergoing surgery. Journal of Health Psychology, 15, 405-415.

Friedler, S., Glasser, S., Azani, L., Freedman, L. S., Raziel, A., Strassburger, D., et al. (2011). The effect of medical clowning on pregnancy rates after in vitro fertilization and embryo transfer. Fertility and Sterility, 95, 2127-2130.

Golan, G., Tighe, P., Dobija N., Perel, A., \& Keidan, I. (2009). Clowns for the prevention of preoperative anxiety in children. A randomized control trial. Journal of Pediatric Anesthesia, 19, 262-266.

Higueras, A., Carretero-Dios, H., Muñoz, J. P., Idini, E., Ortiz, A., Rincon, F., \& PrietoMerino, D. (2006). Effects of a humor-centered activity on disruptive behavior in psychiatric patients in a general hospital psychiatric ward. International Journal of Clinical and Health Psychology, 6, 53-64.

Hirsch, R. D., Junglas, K., Konradt, B., \& Jonitz, M. F. (2010). Humortherapie bei alten Menschen mit einer Depression. Ergebnisse einer empirischen Untersuchung [Humor therapy in the depressed elderly. Results of an empirical study]. Zeitschrift für Gerontologie und Geriatrie, 43, 42-52.

Janke, W., Hüppe, M., \& Erdmann, G. (2003). Befindlichkeitsskalierung anhand von Kategorien und Eigenschaftswörtern [Mood checklist by categories and adjectives]. Würzburg: Department of Psychology, University of Würzburg.

Kingsnorth, S., Blain, S., \& Keever, P. M. (2010). Physiological and emotional response of disabled children to therapeutic clowns: a pilot study. Evidence Based Complementary and Alternative Medicine, 1-10.

Linge, L. (2008). Hospital clowns working in pairs - in synchronized communication with ailing children. International Journal of Qualitative Studies on Health and Well-Being, $3(1), 27-38$.

Linge, L. (2011). Joy without demands: Hospital clowns in the world of ailing children. International Journal of Qualitative Studies on Health and Well-being, 6, 5899.

Linge, L. (2012). Magical attachment: Children in magical relations with hospital clowns. International Journal of Qualitative Studies on Health and Well-being, 7, 11862.

Pinquart, M., Skolaude, D., Zaplinski, K., \& Maier, R. F. (2011). Do clown visits improve psychological and sense of physical well-being of hospitalized pediatric patients? Klinische Pädiatrie, 223, 74-78.

Platt, T., Hofmann, J., Ruch, W., \& Proyer, R. T. (2013). Duchenne display responses towards sixteen enjoyable emotions: Individual differences between no and fear of being laughed at. Motivation and Emotion, 37, 776-786. 10.1007/s11031-013-9342-9.

Ruch, W. (1993). Exhilaration and humor. In M. Lewis \& J. M. Haviland (Eds.), The handbook of emotions (pp. 605-626). New York, NY: Guilford Publications.

Ruch, W., \& Hehl, F.-J. (1998). A two-mode model of humor appreciation: Its relation to aesthetic appreciation and simplicity-complexity of personality. In W. Ruch (Ed.), The 
sense of humor: Explorations of a personality characteristic (pp. 109-142). Berlin, Germany: Mouton de Gruyter.

Ruch, W., \& Hofmann, J. (2012). A temperament approach to humor. In P. Gremigni (Ed.), Humor and health promotion (pp. 79-113), Hauppauge, NY: Nova Science Publishers.

Ruch, W., \& Rath, S. (1993). The nature of humor appreciation: Toward an integration of perception of stimulus properties and affective experience. Humor: International Journal of Humor Research, 6, 363-384.

Ruch, W., Köhler, G., \& van Thriel, C. (1997). To be in good or bad humor: Construction of the state form of the State-Trait-Cheerfulness-Inventory - STCI. Personality and Individual Differences, 22, 477-491.

Ruch, W., Platt, T., Hofmann, J., Auerbach, S., \& Dionigi, A. (2013). Hospital clown research: A positive psychology perspective. Manuscript in preparation.

Stuber, M., Hilber, S. D., Libman Mintzer, L., Castaneda, M., Glover, D., \& Zeltzer, L. (2009). Laughter, humor and pain perception in children: A pilot study. Evidence-Based Complementary and Alternative Medicine 6, 271-276.

Tabachnick, B. G., \& Fidell, L. S. (2013). Using multivariate statistics. Boston: Pearson.

Transcendence. (n.d.). In Merriam-Webster's Online Dictionary. Retrieved from http://www.merriam-webster.com/dictionary/transcendence

Vagnoli, L., Caprilli, S., \& Messeri, A. (2010). Parental presence, clowns or sedative premedication to treat preoperative anxiety in children: What could be the most promising option? Pediatric Anesthesia, 20, 937-943.

Vagnoli, L., Caprilli, S., Roblioglio, B. A., \& Messeri, A. (2005). Clown doctors as a treatment for preoperative anxiety in children: A randomized, prospective study. Pediatrics, 116, 563-567.

Watson, D., \& Tellegen, A. (1985). Toward a consensual structure of mood. Psychological Bulletin, 98, 219-235.

Wild, B., Wetzel, P., Gottwald, U., Buchkremer, G., \& Wormstall, H. (2007). Clowns in der Psychiatrie. Ein Pilotprojekt [A pilot project with clowns in psychiatric clinics]. Nervenarzt, 78, 571-574.

Zweyer, K., Velker, B., \& Ruch, W. (2004). Do cheerfulness, exhilaration, and humor production moderate pain tolerance? A FACS study. Humor: International Journal of Humor Research, 17, 85-119. 
